\title{
Discrete Element Modeling of Powder Flow and Laser Heating in
}

\section{Direct Metal Laser Sintering Process}

\author{
Weng-Hoh Lee, Yi Zhang, Jing Zhang* \\ Department of Mechanical Engineering, Indiana University-Purdue University \\ Indianapolis, Indianapolis, IN, USA \\ *Corresponding author: jz29@iupui.edu; 317-278-7186
}

\begin{abstract}
A novel particle-based discrete element model (DEM) is developed to simulate the whole Direct Metal Laser Sintering (DMLS) process, which includes simplified powder deposition, recoating, laser heating, and holding stages. This model is first validated through the simulation of particle flow and heat conduction in the powder bed, and the simulated results are in good agreement with either experiment in the literature or finite element method. Then the validated model is employed to the DMLS process. The effects of laser power, laser scan speed, and hatch spacing on the temperature distributions in the powder bed are investigated. The results demonstrate that the powder bed temperature rises as the laser power is increased. Increasing laser scan speed and laser hatch spacing will not affect the average temperature increase in the powder bed since energy input is kept same. However, a large hatch spacing may cause non-uniform temperature distribution and microstructure inhomogeneity. The model developed in this study can be used as a design and optimization tool for DMLS process.
\end{abstract}

Keywords: direct metal laser sintering; additive manufacturing; discrete element model; simulation; particle flow; heat transfer

This is the author's manuscript of the article published in final edited form as: 


\section{Introduction}

Direct Metal Laser Sintering is an additive manufacturing (AM) technique that uses a laser fired into a metal powder bed to create a solid structure through a layer-by-layer sintering process [1-3]. DMLS allows the production of complex metallic structures with complex internal and external features. The development of DMLS not only assists in reducing labor cost and time during the product development stage but also opens up new opportunities for creating certain parts that can not be created using traditional manufacturing processes.

In a typical DMLS process, a layer of loose metal powder with a thickness of $0.1 \sim 0.3$ $\mathrm{mm}$ is deposited and distributed onto the powder bed by scratching a recoating blade. Then the powder is sintered or partially melted by a laser source. The laser heat source moves during the sintering process, and a metallic solid layer with designed pattern is formed. Another layer of powder is then deposited and distributed by the recoating blade. By repeating this "recoating and heating" process, a solid part is fabricated [4]. In DMLS processes, laser power, laser scan speed, hatch spacing are the major processing parameters that affect the performance of DMLS fabricated parts.

The growing need of reliable methods to improve the quality of AM parts greatly depends on the quantitative understanding of powder deposition and laser sintering during 3D printing processes. One of the important research aspects of the DMLS process is to understand how metal particles behave mechanically and thermally on the surface of the powder bed during the printing process [5]. The force and heat interactions between the powders play an important role in the definition of the behavior of the powder bed. 
Therefore, in order to understand the mechanical and thermal behavior of the powder during the DMLS process, a particle-based model is needed.

Currently, experimental studies suggest that the properties of DMLS fabricated parts are influenced by powder characteristics and process parameters [6-8]. Although much computational work has been done in recent years, the correlation between the processing parameters and printed material properties is still not fully understood [9]. Computational fluid dynamics have been used to study the formation of melting pool and powder phase change. N'Dri et al. [10] presented an uncertainty quantification model to predict the melting pool size, laser track, and residual stress. Their studies show that simulation results are highly dependent on the accuracy of powder conductivity and heat absorption. Mindt et al.[9] developed a particle-based model to predict the morphology of a printed structure in various processing conditions. Zohdi [11] presented a modular computational framework to combine particle dynamics, laser input, and particle thermodynamics to understand the overall laser sintering process. Herbold et al. [12] conducted a DEM study to show the powder deposition and recoating process in DMLS. In summary, most previous studies were focused on a particular step or process, DEM simulation of the whole DMLS process has not been reported. This work presents a DEM simulation of a DMLS process, including four stages: powder deposition, recoating, laser heating, and holding. Figure 1 shows the flow chart of the DEM simulation in this study. 


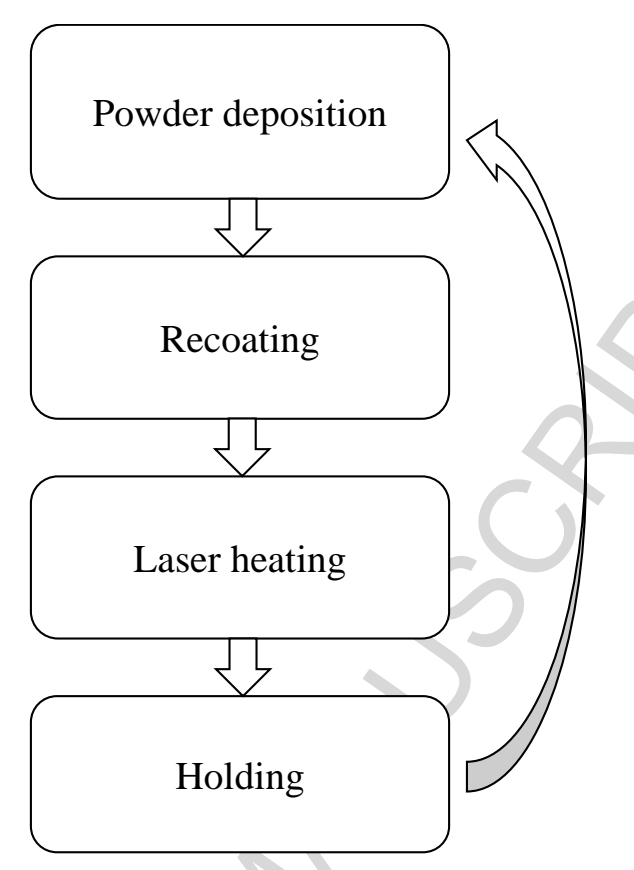

Figure 1: Flow chart of the DEM simulation of DMLS process in this study.

In this work, a novel DEM is developed to study the complete DMLS process. The paper is outlined as follows. Section 2 presents the details of the model. The governing equations, model validations of particle flow, and heat transfer and the DMLS model, are presented. In the DMLS model, powder deposition, recoating, laser heating, and holding processes are investigated. Section 3 summarizes a series of parametric studies. The effects of laser power, laser scan speed, and laser hatch spacing on the powder bed temperature are systematically investigated. Section 4 shows the conclusion and limitation of the model and the direction of future studies. 


\section{Discrete element modeling details}

\subsection{Governing equations}

Discrete element method is a numerical technique that calculates the interaction of a large number of particles [13]. For particle flow simulations, this method calculates defined displacements and rotations of discrete bodies of various types of particle shapes, which can be predicted through the gathering of assembled particles [14]. Particles are simulated through solving the Newton's second law of motion and rigid body dynamics equation combined with specific time-stepping algorithms $[15,16]$. In this study, the LIGGGTS package [17], with a timestep of $0.00005 \mathrm{~s}$, is used to simulate the interaction among metal particles in the DMLS process, by solving the corresponding governing equations (Eqs. 1 and 2 for translational and rotational motion, respectively)[16]:

$$
\begin{gathered}
m_{i} \ddot{x}_{i}=m_{i} g+\sum_{j} F_{i j} \\
I_{i} \ddot{\theta}=\sum_{i}\left(r_{i j} \cdot F_{i j}\right)
\end{gathered}
$$

with $\ddot{x}_{\imath}$ translational acceleration, $m_{i}$ mass of the particles $i, g$ acceleration due to gravity, $F_{i j}$ force at contact with neighboring particles $j, r_{i j}$ vector directed from the center of the particle $i$ to the contact point with particle $j$, and $I_{i}$ the mass moment of inertia of the particle $i$. 
For inter-particle interactions, Hertzian potential force with no cohesion reaction is used. As shown in the particle flow validation study in section 2.1.1, the case with no cohesion gives good agreement with experiment. The Hertzian formula to compute the pair potential forces are as follows [18-20]:

$$
\begin{gathered}
F_{h k}=\left(k_{n} \delta n_{i j}-m_{e f f} \gamma_{n} v_{n}\right)-\left(k_{t} \Delta s_{t}+m_{e f f} \gamma_{t} v_{t}\right) \\
F_{h z}=\sqrt{\delta} \sqrt{\frac{R_{i} R_{i}}{R_{i}+R_{j}}} F_{h k}=\sqrt{\delta} \sqrt{\frac{R_{i} R_{i}}{R_{i}+R_{j}}}\left[\left(k_{n} \delta n_{i j}-m_{e f f} \gamma_{n} v_{n}\right)-\left(k_{t} \Delta s_{t}+m_{e f f} \gamma_{t} v_{t}\right)\right]
\end{gathered}
$$

with $R_{i}$ and $R_{j}$ are the radii of particle $i$ and $j$, respectively, $\delta$ the overlap distance of two particles, $k$ the elastic constant, $\gamma$ the viscoelastic damping constant, $\Delta s$ the displacement vector between the two spherical particles which is truncated to satisfy a frictional yield criterion, $n_{i j}$ the unit vector along the line connecting the centers of the two particles, $v$ the component of the relative velocity of the two particles; indices $n$ and $t$ referring to normal and tangential contact respectively. $F_{h k}$ the force calculated using the Hookean style, $F_{h z}$ the force calculated using the Hertzian style, and $m_{\text {eff }}$ the effective mass of two particles.

The heat distribution in the powder bed is determined by combining the heat conduction through particle contacts and the heat generation due to the laser source [21]: 


$$
\begin{gathered}
\dot{Q}_{p i-p j}=h_{c, i-j} \Delta T_{p i-p j} \\
h_{c, i-j}=\frac{4 k_{p i} k_{p j}}{k_{p i}+k_{p j}}\left(A_{\text {contact }, i-j}\right) \\
m_{p} c_{p} \frac{d T_{p, i}}{d t}=\sum \dot{Q}_{p i-p j}+\dot{Q}_{p i, \text { source }}
\end{gathered}
$$

with $h_{c}$ the heat transfer coefficient, $k_{p i}$ the thermal conductivity of particle $i, c_{p}$ the specific thermal capacity, $A_{\text {contact, } i-j}$ the particle contact area, $\dot{Q}_{p i-p j}$ the heat flux between particles $i$ and $j, T_{i}$ the temperature of particle $i$, and $m$ the mass of the particle.

\subsection{Model validations}

\subsubsection{Particle flow model validation}

Powder deposition and recoating in the DMLS process are validated by a particle flow model. The model simulates the powder discharge process from a hopper, with same conditions as the experiments conducted by González-Montellano [22]. As shown in Figure 2a, the height of the hopper is $700 \mathrm{~mm}$ and its sides are $250 \mathrm{~mm}$. The bottom of the hopper has an opening of $57.5 \mathrm{~mm}$. Total 14,000 particles are inserted into the hopper. The coefficient of restitution and coefficient of friction used in this validation study are 0.62 and 0.3 respectively. The density of the particles is $2,516 \mathrm{~kg} / \mathrm{m}^{3}$ with a Poisson's ratio of $0.22[22]$. 
The first step of this example is to compare the general particle flow pattern as shown in Figure $2 \mathrm{~b}$. The figure shows particles flowing through the hopper with the same condition shown in González-Montellano's work [22]. With the correct prediction of particle flow pattern, the time required for all the particles to flow out of the hopper is calculated. The computed time in this validation LIGGGHTS model is $29.4 \mathrm{~s}$, and the experimentally measured time is $29.3 \mathrm{~s}$ [22], with less than $1 \%$ difference between the validation and experiment. Therefore, the particle flow model is successfully validated.

It is also noted that, for inter-particle interactions, no cohesion reaction is used in the model. Several parametric studies have been conducted showing that cohesion increases the time of discharge. The case with no cohesion gives good agreement with the experiment.

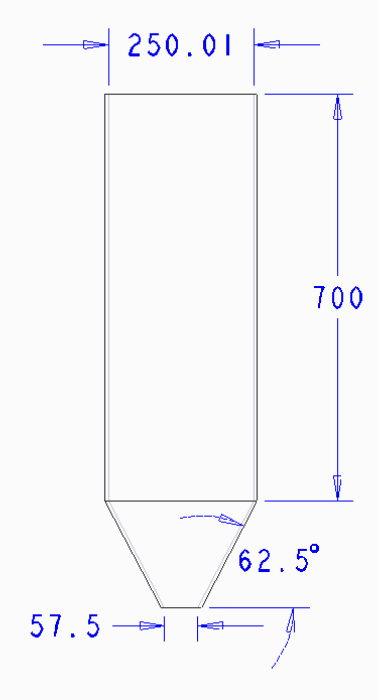

(a)

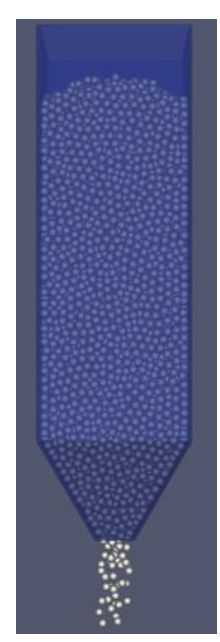

(b) 
Figure 2: Particle flow validation model. (a) hopper dimensions (unit: mm), (b) discharge of partilces from the hopper.

\subsubsection{Heat transfer model validation}

A transient heat transfer validation study was also conducted. The heat transfer DEM simulation used in the validation is a powder bed with a height of $0.214 \mathrm{~m}$, a length of 1 $\mathrm{m}$ and a width of $0.3 \mathrm{~m}$. The particle sizes used is $0.04 \mathrm{~mm}$ in diameter with a density of $8000 \mathrm{~kg} / \mathrm{m}^{3}$. As shown in the governing equations $5-7$, heat conduction is the only heat transfer mechanism in this transient model. The boundary condition includes the definition of heat walls of $300^{\circ} \mathrm{C}$ at the left end and $0^{\circ} \mathrm{C}$ at the right end of the powder bed, with the initial temperature of $0^{\circ} \mathrm{C}$.

The time-dependent temperature distribution from the DEM validation simulation is compared against one-dimensional finite element model (FEM) using COMSOL Multiphysics. The FEM uses the same conditions as DEM, including porosity-dependent material properties, boundary, and initial conditions.

Figure 3 shows the temperature distributions using the results obtained from the DEM heat transfer model and the FEM at three moments: 9, 12, and $15 \mathrm{~s}$. As shown in the figure, the predicted temperature distributions using the DEM are in good agreement with 
the FEM results in all three moments. Therefore, the LIGGGHTS package is capable of correctly simulating heat transfer in DMLS processes.

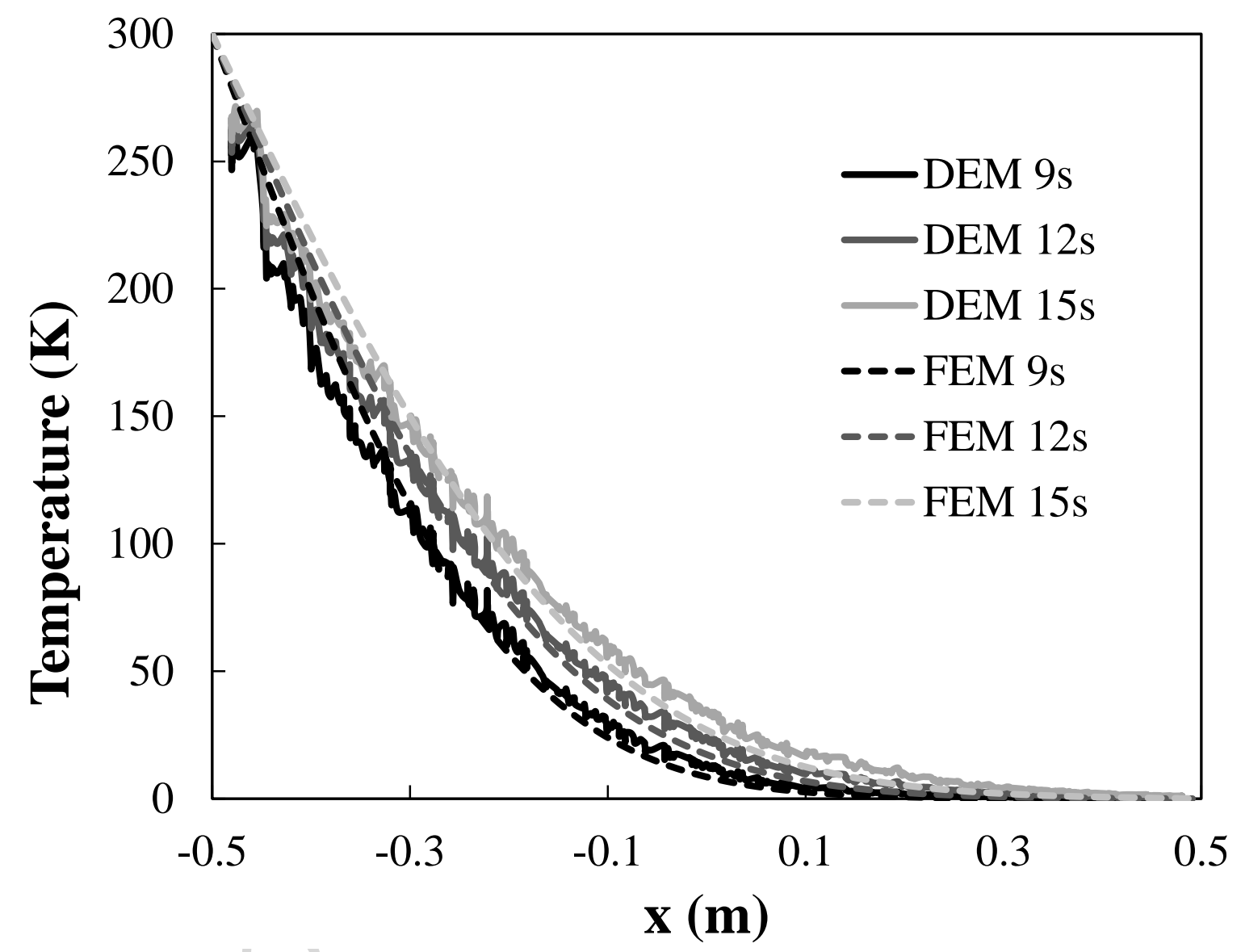

Figure 3: Temperature distribution and evolution of thermal conduction simulation using DEM and FEM.

\subsection{DMLS process model}

After model validations, the DMLS process with 15-5 PH1 stainless steel powder is investigated in this study. Simplified powder deposition from the top of the powder bed 
was used. The vertical deposition from the top is different from the actual DMLS process in which powder is pushed by a recoater from the side, however, the simplification is needed to make the problem numerically feasible. The top view of the powder bed along with the laser scan path is shown in Figure 4. The dimension of the simulation box of the powder bed is $1.8 \mathrm{~mm}$ (length) $\times 0.9 \mathrm{~mm}$ (width) $\times 1 \mathrm{~mm}$ (height) The laser scan path defined in the simulation is illustrated using red lines, with arrows showing the laser scan direction.

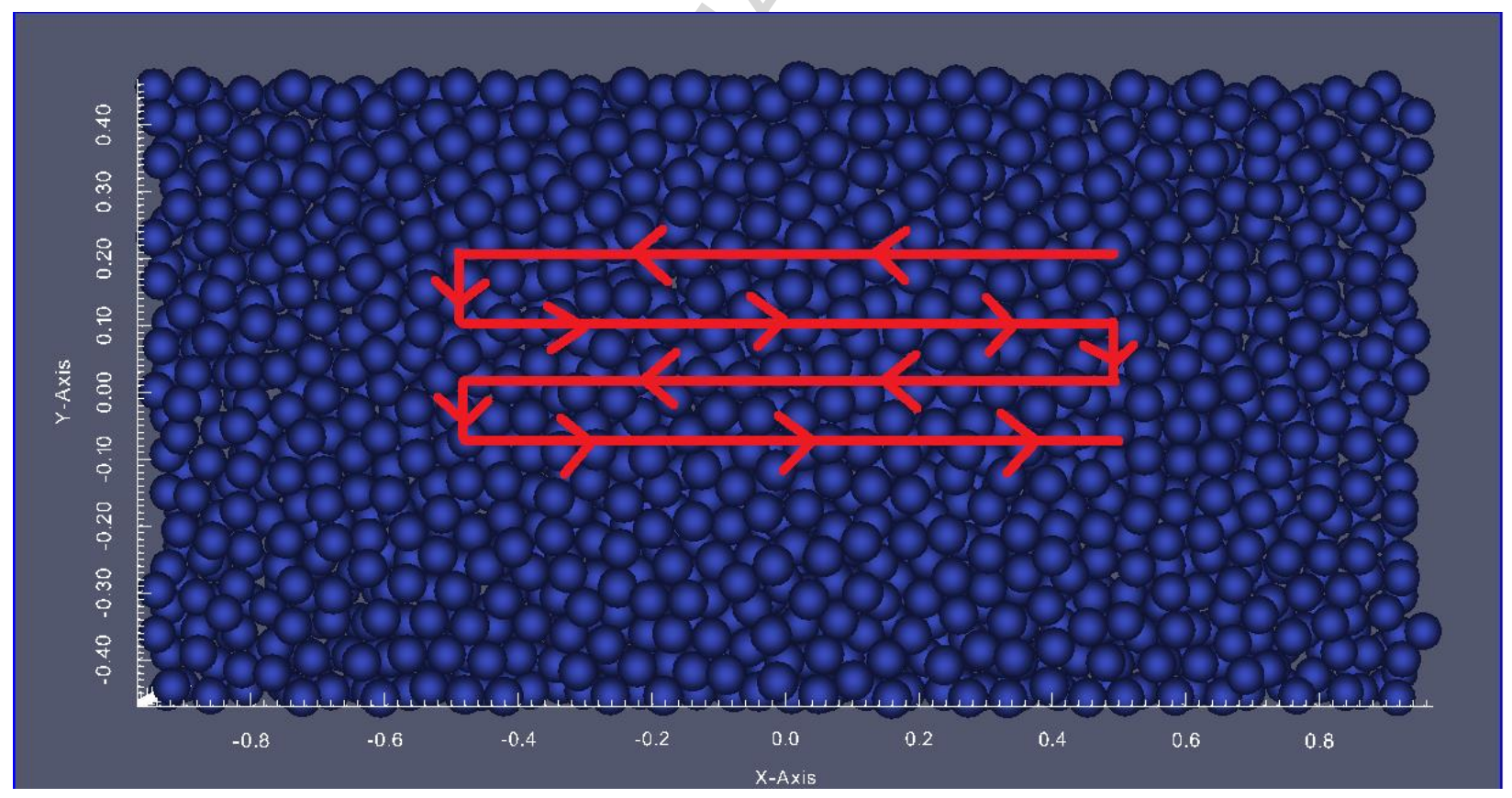

Figure 4: Top view of the powder bed dimensions (unit: $\mathrm{mm}$ ) used in the DMLS process model. Laser scan path is represented by the red line.

A simulation box with non-periodic and shrinkage wrapped boundary conditions is used 
to relate the particle behavior with its surrounding volume. For the initial stage, the gravitational effect on the powder bed is considered for the whole volume and each particle presented in the powder bed. The powder bed is initially deposited with particles at room temperature of $294.16 \mathrm{~K}$. Next, a recoating process is applied to smoothen the powder bed top surface. Although in the actual DMLS process, the powder is deposited at the sides of the building platform and recoated by a recoating blade, an assumption is made to make the problem numerically feasible, where the actual deposition of the powder in DMLS is replaced by a vertical deposition of the particles on top of the powder bed. Then a laser heating is performed on the powder bed followed by a holding process before depositing the second layer.

The laser heating is implemented by defining the temperature of a region in the powder bed corresponding to the laser source size $(300 \mu \mathrm{m}$ diameter). The laser intensity distribution is not considered in the model, and a uniform laser power distribution is assumed in this study. Since in the current simulation package, the temperature is defined uniformly within each particle, it is impractical to represent a temperature distribution inside a small heated region containing a few particles. The temperature of the heated particles is calculated through the Rosenthal solution for temperature in an infinite half-space [23]:

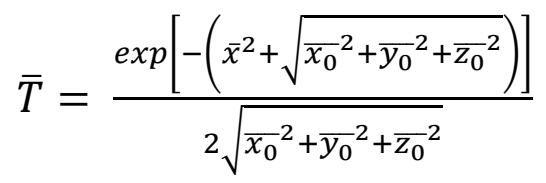

where 


$$
\begin{gathered}
\bar{T}=\frac{T-T_{0}}{\left(\frac{\alpha Q}{\pi k}\right)\left(\frac{\rho c V}{2 k}\right)} \\
\overline{x_{0}}=\frac{x_{0}}{\left(\frac{2 k}{\rho c V}\right)}, \overline{y_{0}}=\frac{y_{0}}{\left(\frac{2 k}{\rho c V}\right)}, \overline{z_{0}}=\frac{z_{0}}{\left(\frac{2 k}{\rho c V}\right)},
\end{gathered}
$$

with $V$ the scan speed in x-coordinate, $Q$ impinging energy absorbed, $\alpha Q$ the fraction of impinging energy absorbed, $x_{0}, y_{0}$ and $z_{0}$ the laser beam relative coordinates at $x, y$ and $z$ directions respectively, $T_{o}$ initial temperature, $\rho$ the density, $c$ specific heat, and $k$ the thermal conductivity of the powder.

Table 1 summarizes the material properties of 15-5 PH1 stainless steel used in the DMLS simulations. It is assumed that the particles are spherical and incompressible, and density of the particle is constant. The materials properties are temperature-independent. Furthermore, radiation, viscous heating as well as natural convection are not considered in this study due to their small contributions to heat transfer process [24-26].

Table 1: Material parameters of 15-5 PH1 used in the simulations

\begin{tabular}{|l|l|}
\hline Parameter & Value \\
\hline Particle Diameter $(\mathrm{mm})$ & 0.03 \\
Density $\left(\mathrm{kg} / \mathrm{m}^{3}\right)$ & 7800 \\
Coefficient of restitution & 0.7 \\
Coefficient of friction & 0.05 \\
Young's modulus $(\mathrm{GPa})$ & 190 \\
Poisson's ratio & 0.3 \\
Gravity acceleration $\left(\mathrm{m} / \mathrm{s}^{2}\right)$ & 9.81 \\
Thermal conductivity $(\mathrm{W} / \mathrm{m} / \mathrm{K})$ & 22.6 \\
Heat capacity $(\mathrm{J} / \mathrm{kg} / \mathrm{K})$ & 460 \\
\hline
\end{tabular}




\section{Results and discussion}

\subsection{Sequential schematics of the DMLS process}

Figure 5 shows the sequential schematics of the simulated DMLS process, which corresponds to Figure 1. Four stages of the DMLS process, powder vertical deposition, recoating, laser heating, and holding, are simulated. The particles are labeled with colors to present their temperatures. The particles in red are with higher temperatures, while the particles in blue are with lower temperature values.

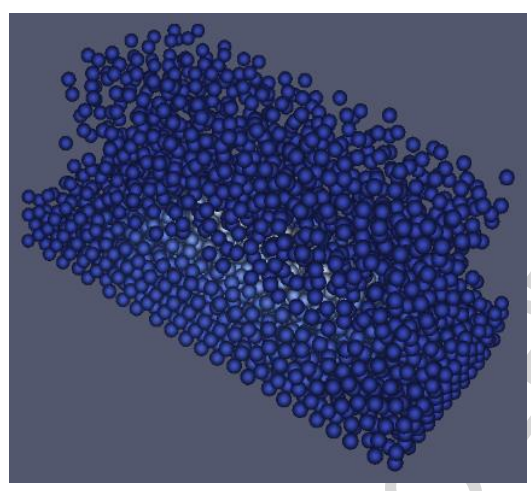

(a)

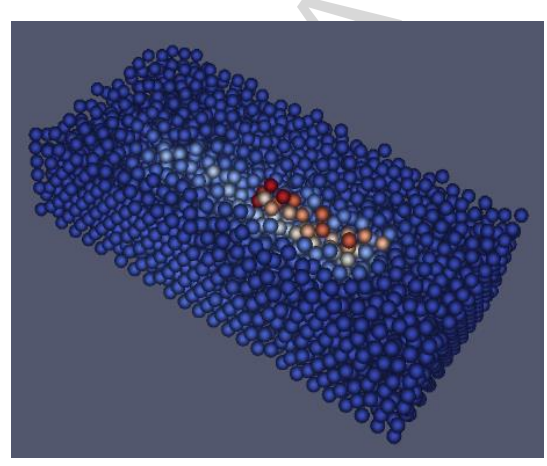

(c)

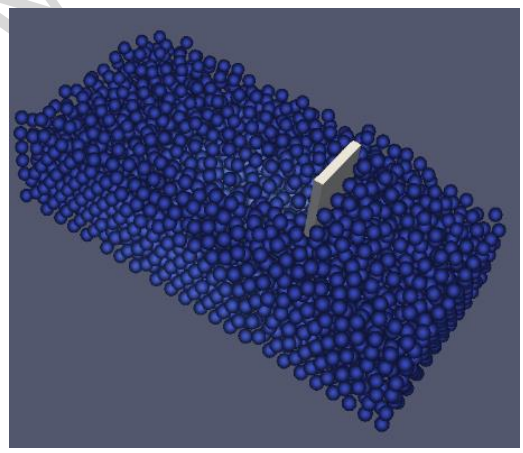

(b)
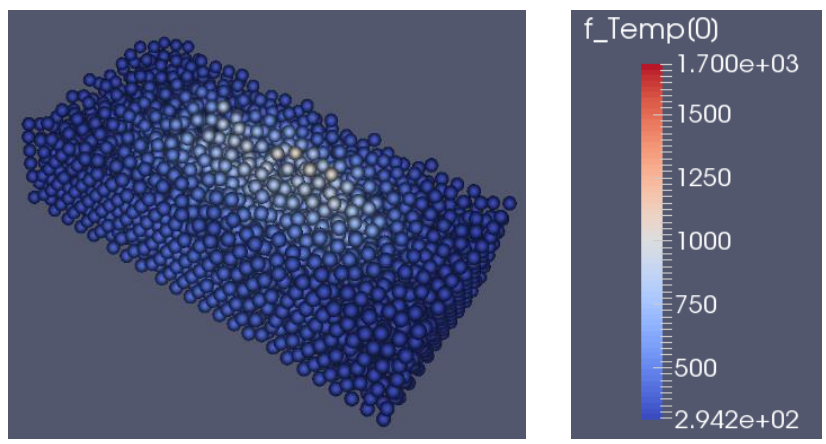

(d) 
Figure 5: Temperature distributions in the DMLS process simulations. (a) vertical deposition of particles, (b) recoating process, (c)laser heating of particles, and (d) holding period. The particles are labeled using colors to present their temperature (unit: K).

In this work, the effects of laser heating parameters, which includes laser power, scan speed, and hatch spacing, on the temperature distribution in the powder bed are analyzed. The temperature distributions are visualized, and the average temperature of the powder bed versus time are plotted to understand the behavior of thermal history.

\subsection{Effect of laser power on temperature in powder bed}

In order to understand the effect of laser power on the powder bed temperature, two laser powers, $300 \mathrm{~W}$ and $100 \mathrm{~W}$ are used in this simulation. For both cases, the speed of the laser is kept constant at $800 \mathrm{~mm} / \mathrm{s}$ and the hatch spacing is set fixed at $0.1 \mathrm{~mm}$. Figure 6 and Figure 7 show the temperature and heat flux distributions in the powder bed using $300 \mathrm{~W}$ and $100 \mathrm{~W}$ laser sources, respectively. For temperature distribution (Figure 6a and Figure 7a), the maximum temperature of the powder bed using $300 \mathrm{~W}$ is higher than that in $100 \mathrm{~W}$. However, the relative temperature distributions in the heated region are similar in two cases. The heat flux is calculated using temperature gradient. As shown in Figure $6 \mathrm{~b}$ and Figure $7 \mathrm{~b}$, the heat flux in higher laser power $300 \mathrm{~W}$ is much higher than that in $100 \mathrm{~W}$, also inhomogeneous in the $300 \mathrm{~W}$ case. Sintering is a thermally activated process, therefore the $300 \mathrm{~W}$ laser source is expected to promote the sintering process. 


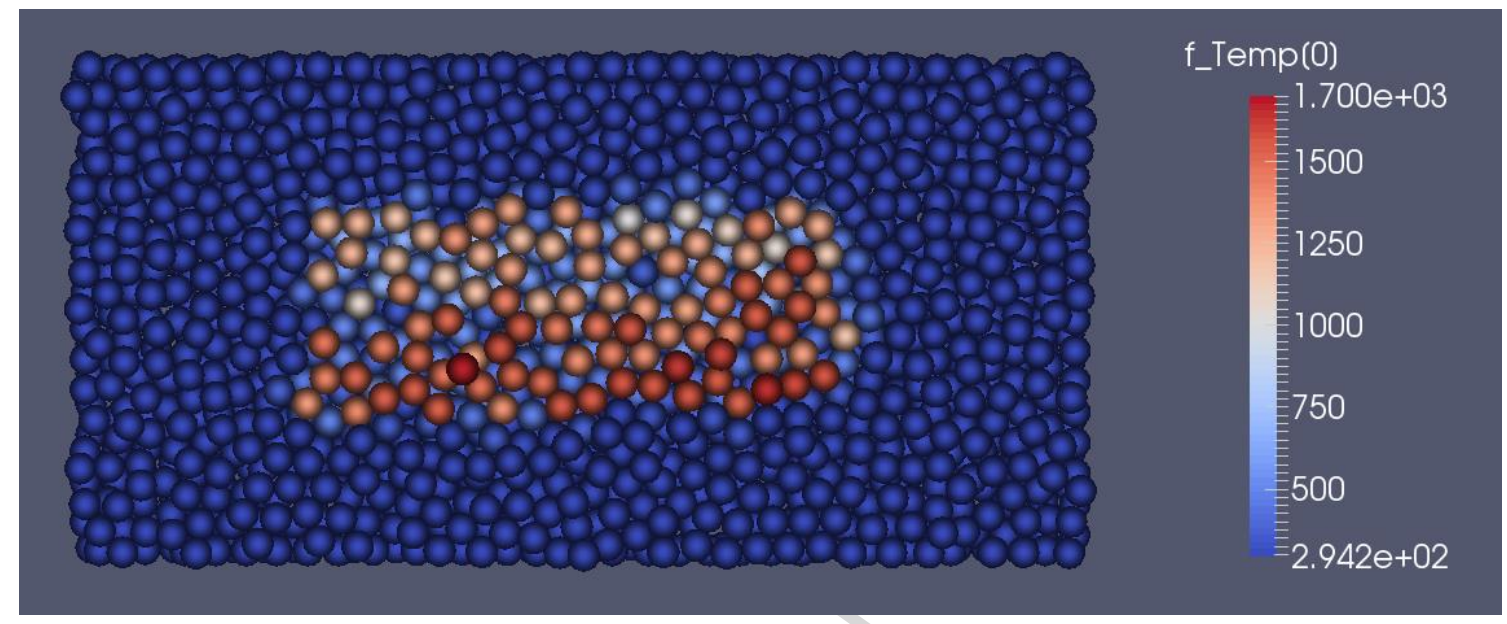

(a)

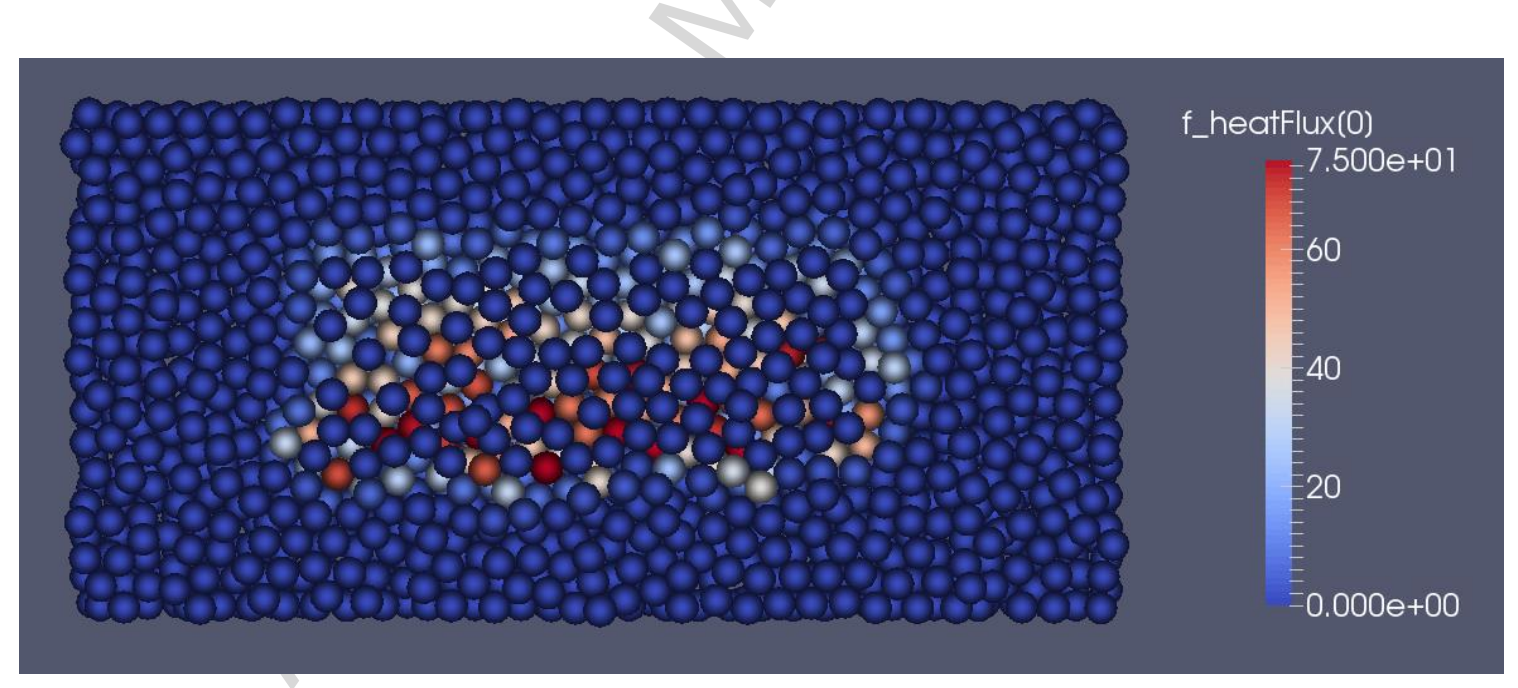

(b)

Figure 6: (a) Temperature distribution (unit: K), and (b) heat flux distribution (unit: W) using $300 \mathrm{~W}$ laser power. 


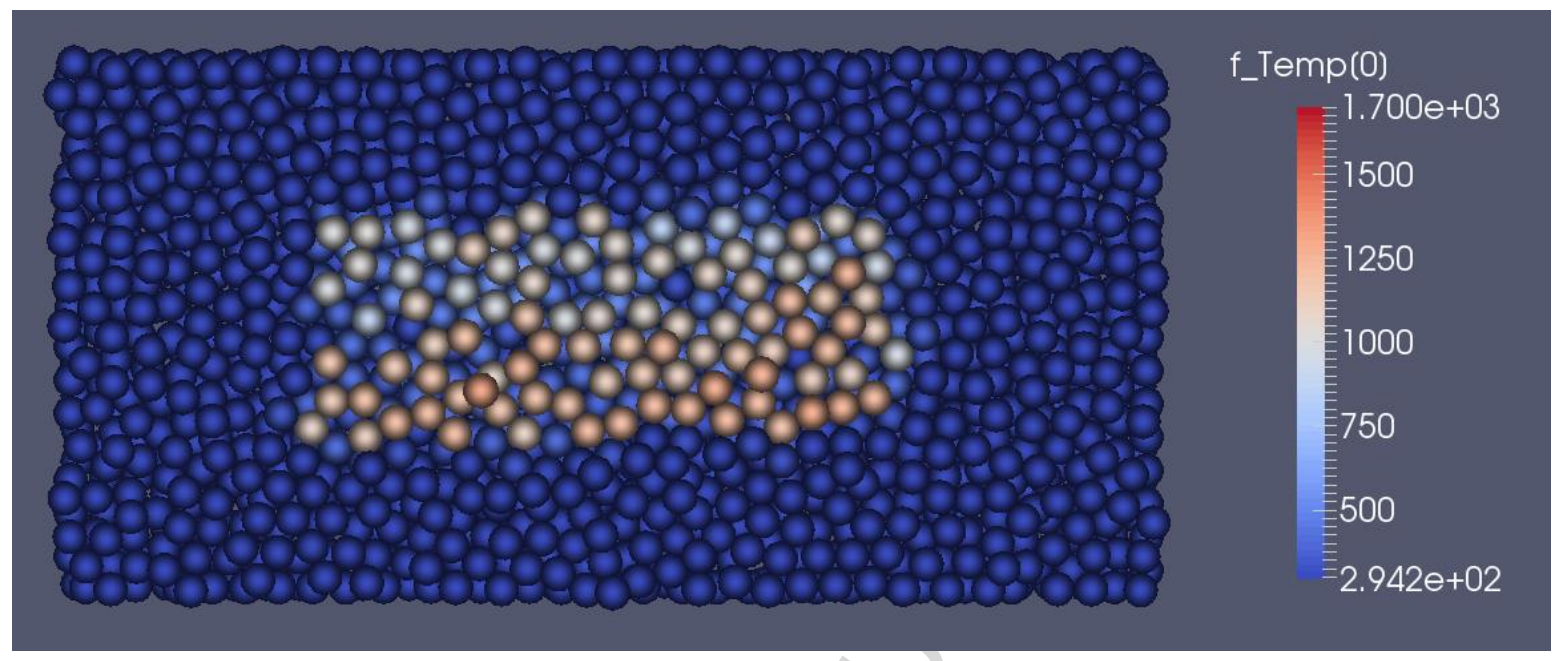

(a)

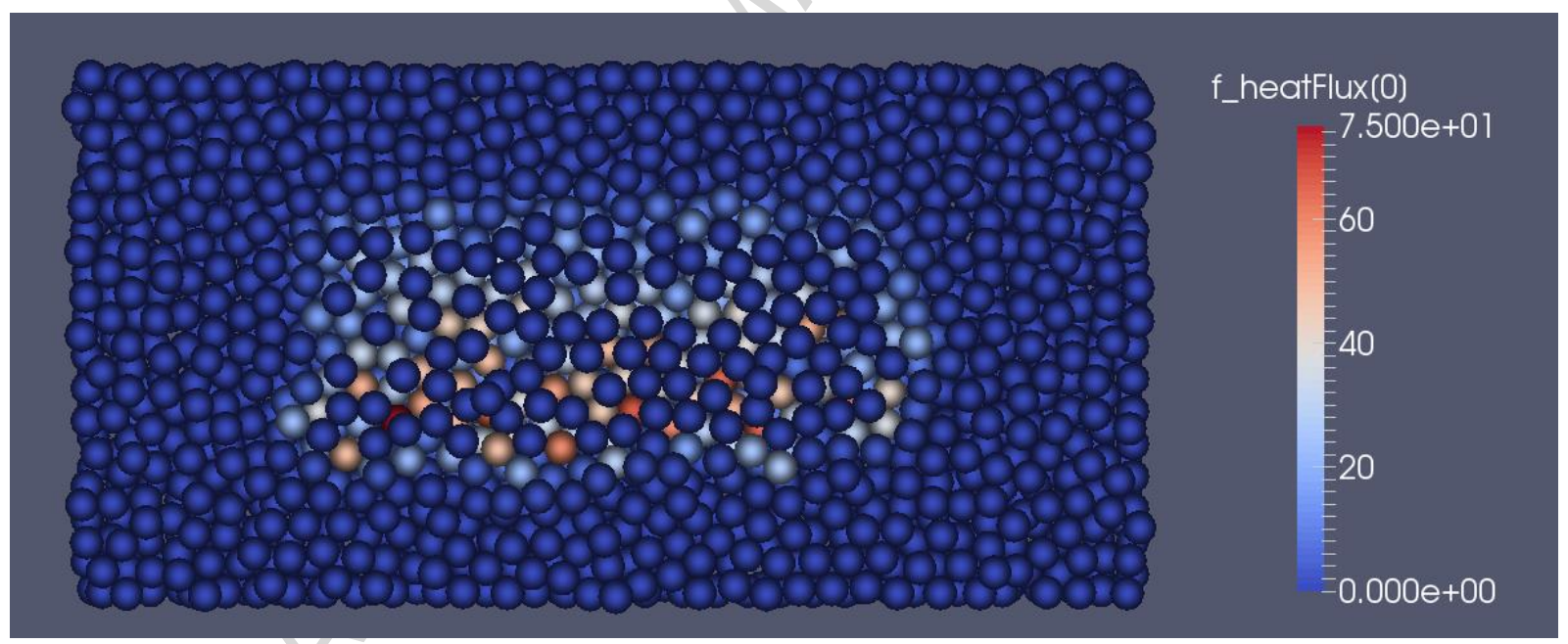

(b)

Figure 7: (a) Temperature distribution (unit: K), and (b) heat flux distribution (unit: W) using $100 \mathrm{~W}$ laser power. 
The average temperatures in the powder bed of $100 \mathrm{~W}$ and $300 \mathrm{~W}$ are plotted in Figure.

8. The maximum average temperature produced by the $300 \mathrm{~W}$ laser can reach up to 383

$\mathrm{K}$ whereas the $100 \mathrm{~W}$ laser only reaches up to $358 \mathrm{~K}$. This is consistent with the Rosenthal solution in Equation 8, where the melt pool temperature during the sintering process increases with increasing laser power when the laser scan speed is kept constant.

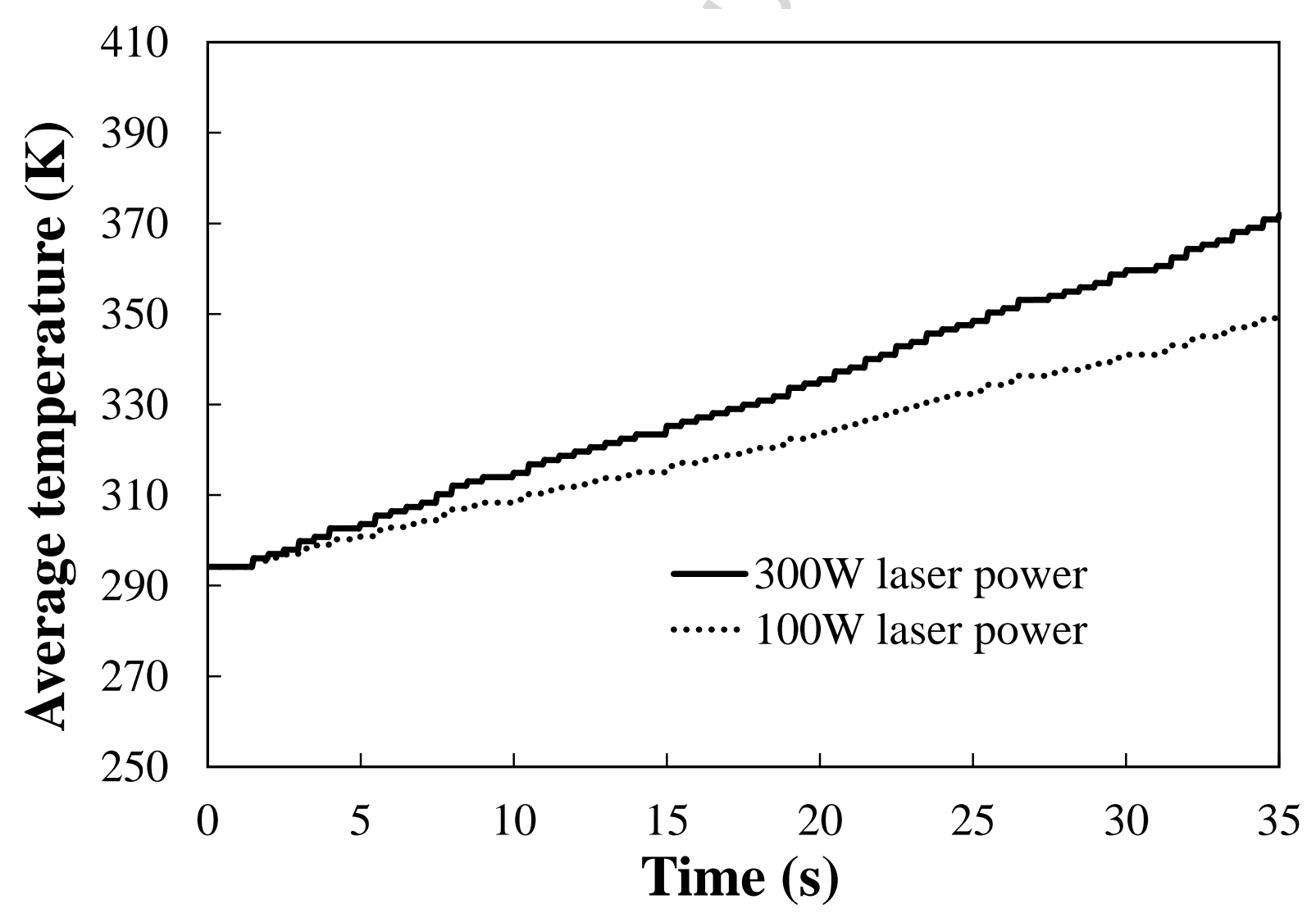

Figure 8: Average temperature of the powder bed versus time for $100 \mathrm{~W}$ and $300 \mathrm{~W}$ laser powers. 


\subsection{Effect of laser scan speed on temperature in powder bed}

In this simulation, the effect of laser scan speed on the temperature during the sintering process is studied. Two laser scan speeds, $1000 \mathrm{~mm} / \mathrm{s}$ and $800 \mathrm{~mm} / \mathrm{s}$, are studied based on the specifications of EOSINT M280 machine. In this study, a constant $300 \mathrm{~W}$ laser power and constant hatch spacing of $0.1 \mathrm{~mm}$ are used. Figure 9 and Figure 10 show the temperature distribution and heat flux of $1000 \mathrm{~mm} / \mathrm{s}$ and $800 \mathrm{~mm} / \mathrm{s}$ scan speed, respectively.

Comparing Figures 9a and 10a, at the same moment, fast scan at $1000 \mathrm{~mm} / \mathrm{s}$ has a larger sintered area than the $800 \mathrm{~mm} / \mathrm{s}$. The temperature distributions in the two scan speeds are similar. In terms of heat flux in Figures $9 \mathrm{~b}$ and $10 \mathrm{~b}$, no substantial difference is found. The differences in heat flux of the two powder bed conditions would only be affected by the laser power used and hatch spacing. In general, increasing laser scan speed will not affect the heat flux in the powder bed, but it reduces the total laser heating time. 

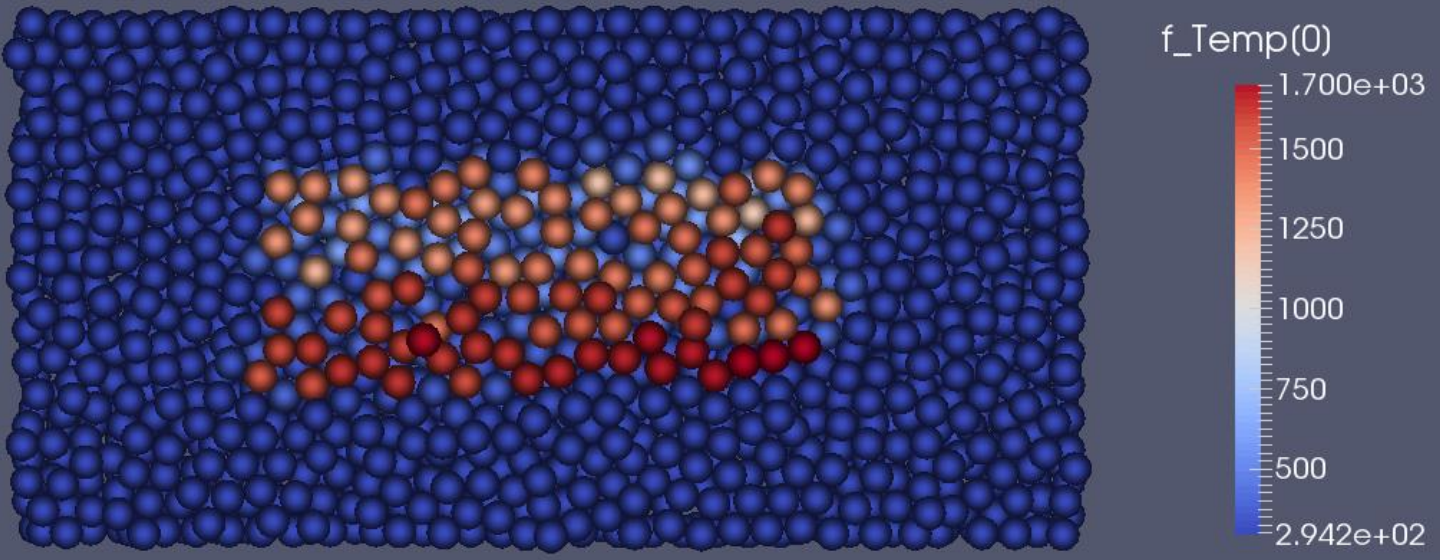

(a)

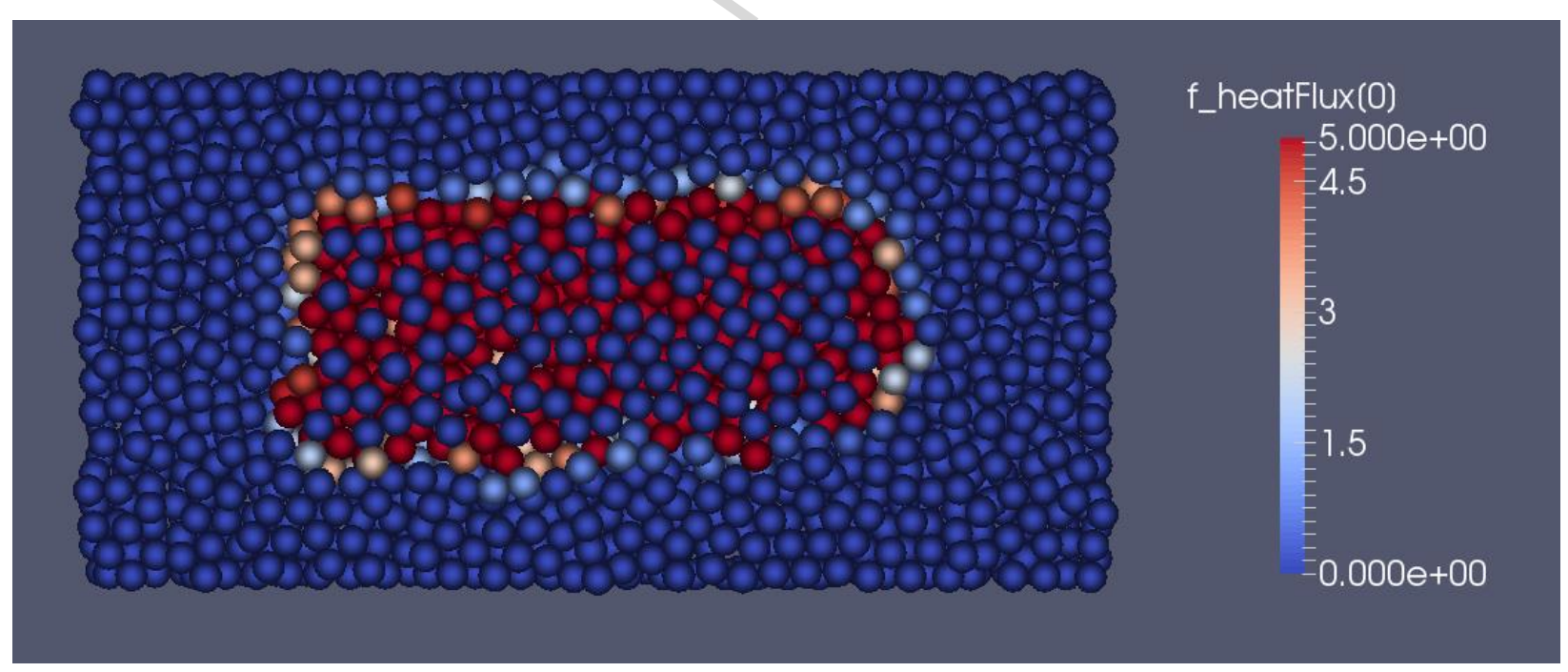

(b)

Figure 9: (a) Temperature distribution (unit: K) and (b) heat flux distribution(unit: W) using $1000 \mathrm{~mm} / \mathrm{s}$ laser scan speed. 


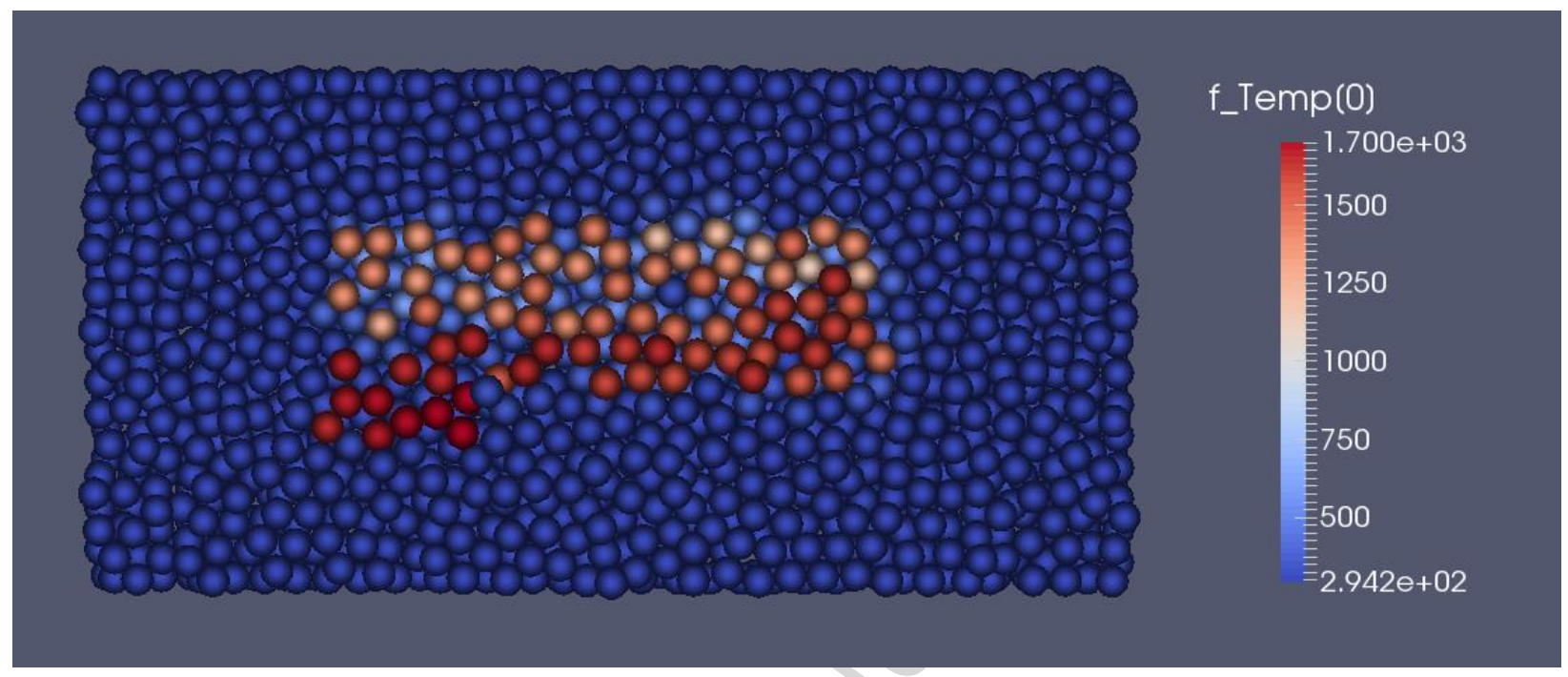

(a)

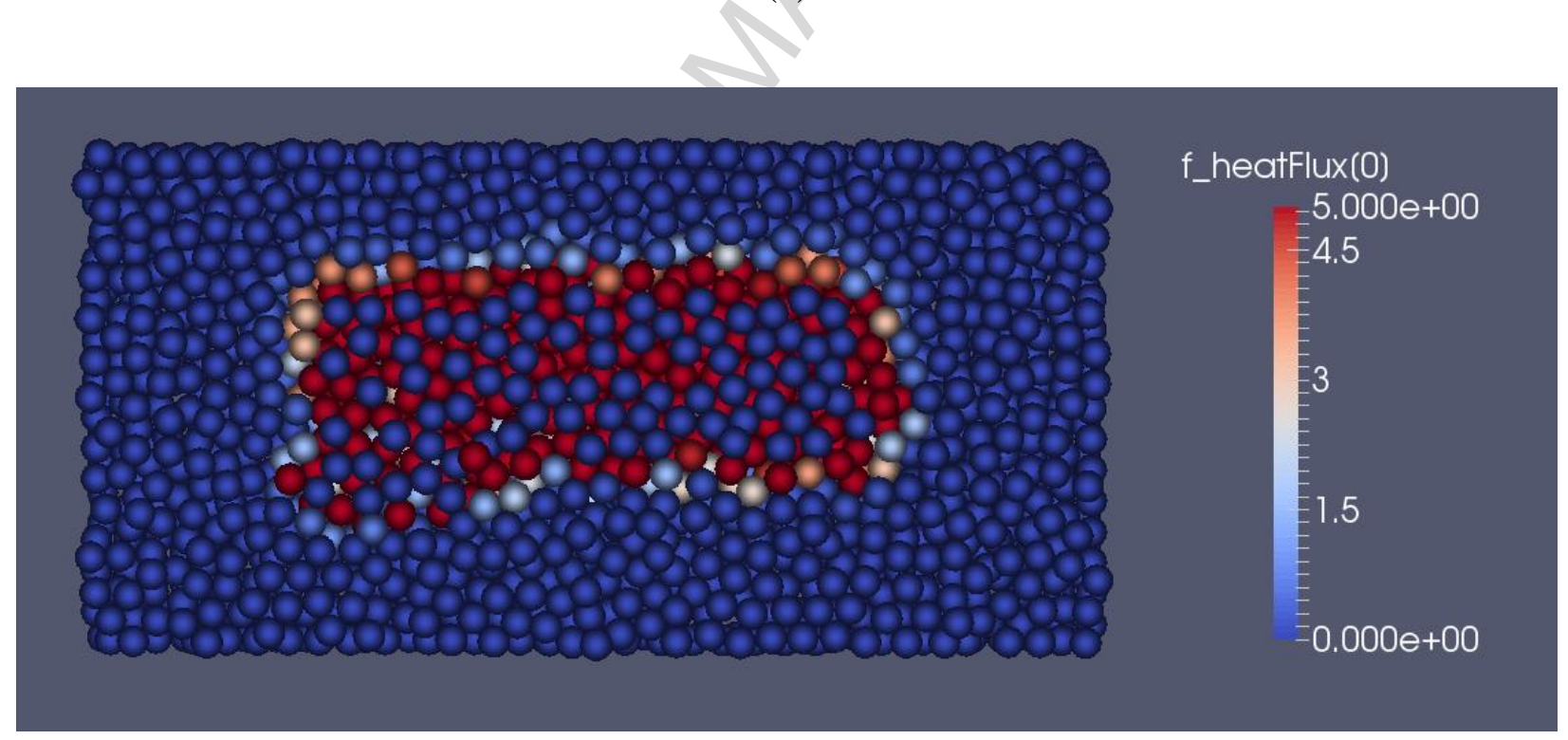

(b)

Figure 10: (a) Temperature distribution (unit: K) and (b) heat flux distribution (unit: W) using $800 \mathrm{~mm} / \mathrm{s}$ laser scan speed. 


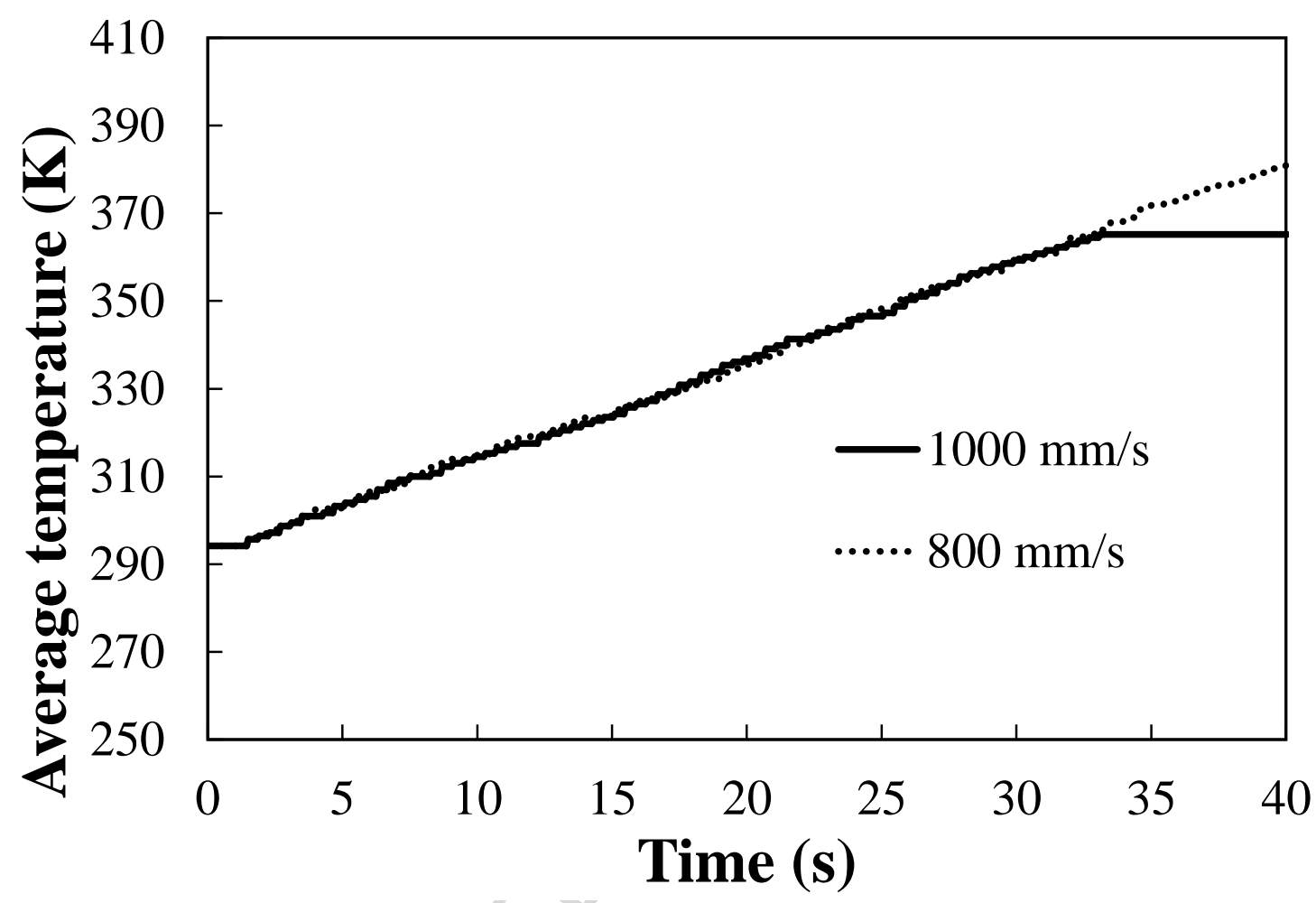

Figure 11: Average temperature of the powder bed versus time using $800 \mathrm{~mm} / \mathrm{s}$ and 1000 $\mathrm{mm} / \mathrm{s}$ laser scan speeds.

In order to quantitatively compare the difference between the two scan speeds, the average temperature evolutions in the powder bed are plotted in Figure 11. As shown in the figure, the $1000 \mathrm{~mm} / \mathrm{s}$ completes the laser scan process faster than the $800 \mathrm{~mm} / \mathrm{s}$ case, and proceeds to holding period earlier. The two temperature curves are very close, since the same laser power is applied, or the same amount of energy input at the same time. 
Temperature increase in the powder bed should be proportional to the amount of energy input. In this case, the power (energy per unit time) is kept constant. Therefore the total amount of energy added to the bed, and the final temperature, are approximately $20 \%$ lower for the $1000 \mathrm{~mm} / \mathrm{s}$ laser scan speed than the $800 \mathrm{~mm} / \mathrm{s}$, as shown in Figure 11 .

\subsection{Effect of laser hatch spacing on temperature in powder bed}

The effect of the laser hatch spacing on the temperature distribution of the powder bed is also studied. A fixed $300 \mathrm{~W}$ laser power and $800 \mathrm{~mm} / \mathrm{s}$ laser scan speed are used for the two cases while changing the hatch spacing with values of $0.1 \mathrm{~mm}$ and $0.2 \mathrm{~mm}$. Figure 12 and Figure 13 show the temperature distributions and heat flux of the powder bed of $0.1 \mathrm{~mm}$ and $0.2 \mathrm{~mm}$, respectively. Figure 12 has a smooth temperature gradient, while Figure 13 has a temperature discontinuity between laser scan lines. Therefore, a large hatch spacing may cause non-uniform temperature distribution and microstructure inhomogeneity.

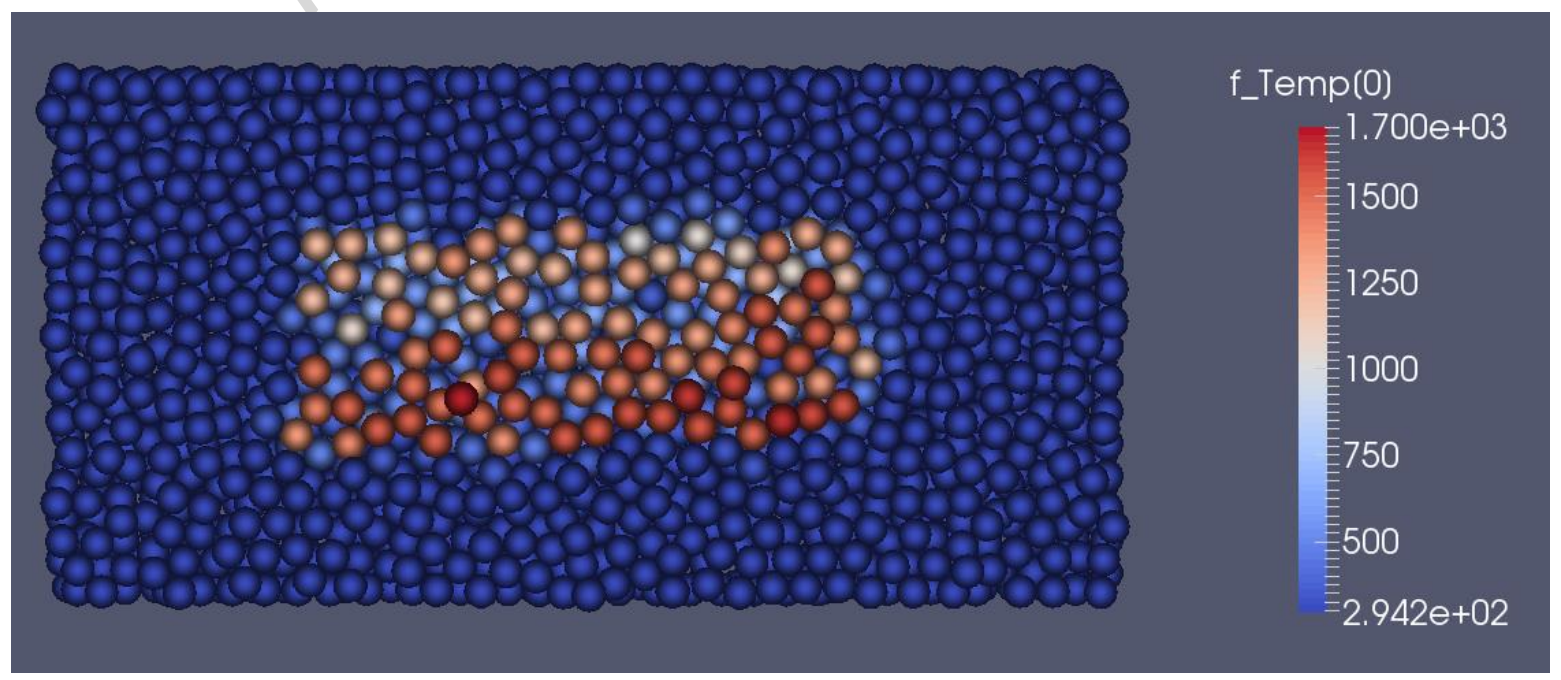


(a)

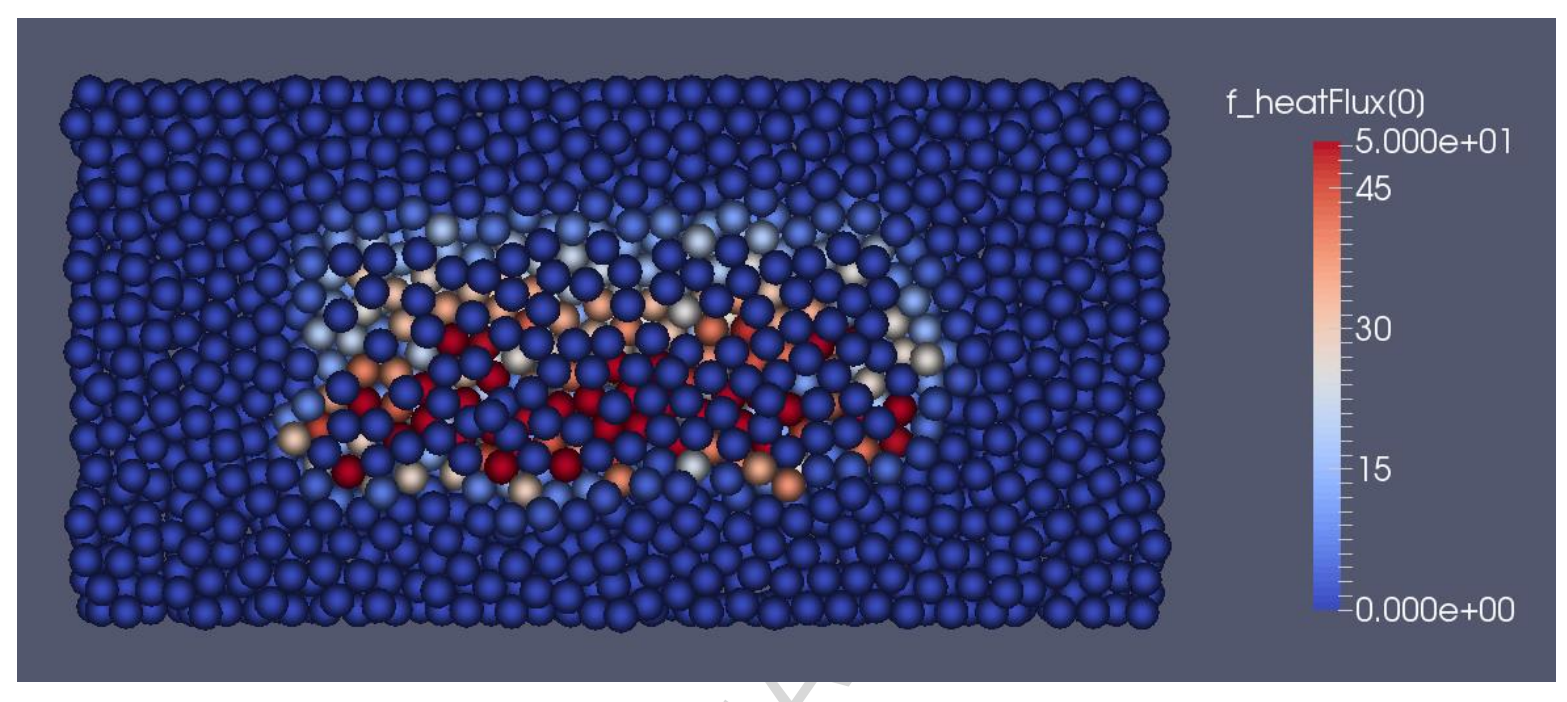

(b)

Figure 12: (a) Temperature distribution, and (b) heat flux distribution using $0.1 \mathrm{~mm}$ hatch spacing. 


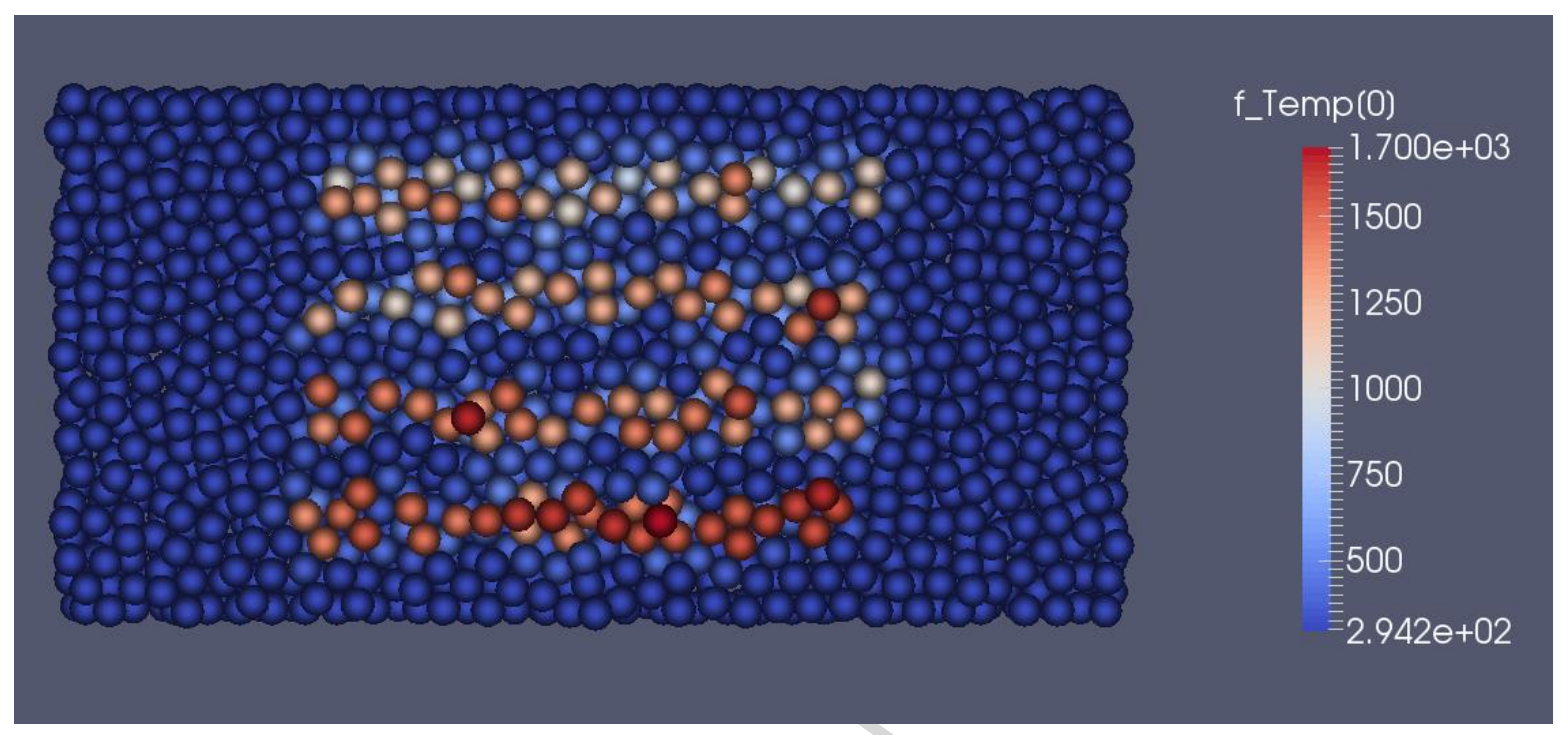

(a)

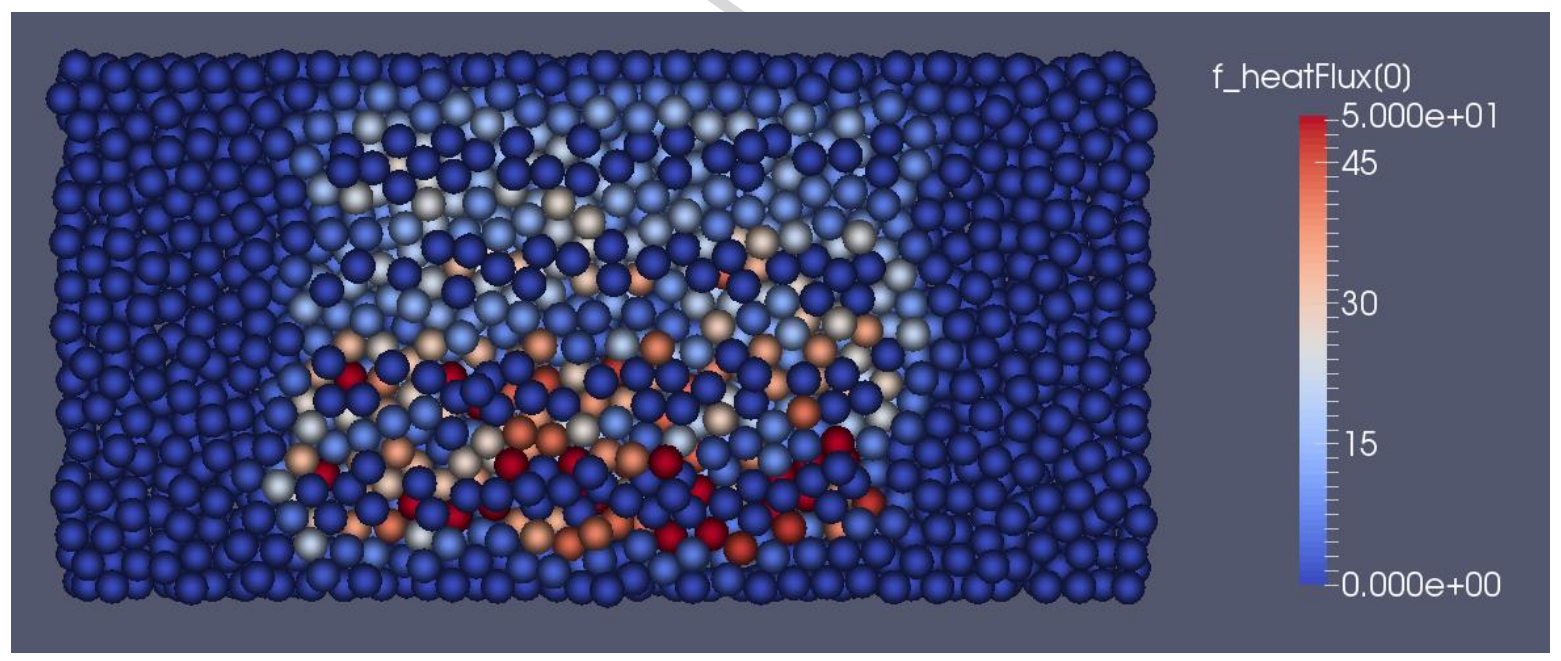

(b)

Figure 13: (a) Temperature distribution, and (b) heat flux distribution using $0.2 \mathrm{~mm}$ hatch spacing. 


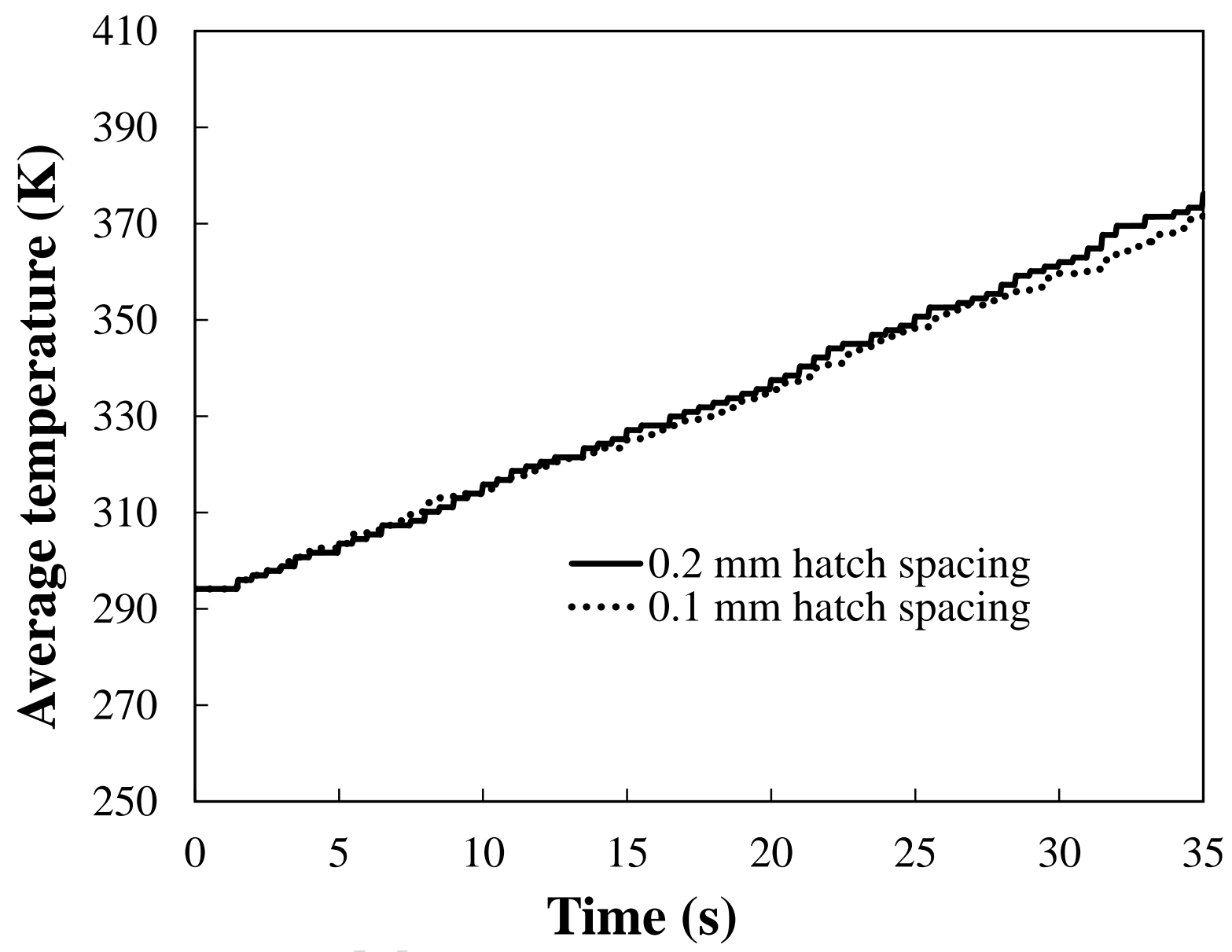

Figure 14: Average temperature in the powder bed versus time using $0.1 \mathrm{~mm}$ hatch spacing and $0.2 \mathrm{~mm}$ hatch spacing.

Figure 14 shows that the average temperatures in the powder bed are close between the two hatch spacings. This is because the total laser energy input and scan speed are the same for both cases. It is noted that although the average temperatures in the powder bed are the same (Figure 14), the localized temperature distributions and heat flux (Figure 12 and Figure 13) are different. With a larger hatch spacing as in Figure 12, the temperature distribution and heat flux are less homogenous. It also shows that a larger hatch spacing 
would create a greater heat flux distribution on the powder bed despite a fixed laser power is used during the sintering process. In an actual printing process, the difference in temperature distribution will lead to a difference in printed part porosity and pore distribution.

It is noted that the laser intensity distribution is not considered in the current model due to limitation of the software. In actual DMLS processes, the real intensity distribution of the laser may play a role. When studying the effect of hatch spacing, this effect may become important, as this could influence the minimal overlap needed.

\section{Conclusion}

In this study, a novel DEM based DMLS process model is developed. The model provides a powerful tool for DMLS process design and optimization. The major conclusions are summarized below.

1. The presented DEM based model is capable to simulate the whole DMLS process, including simplified powder deposition, recoating, laser heating, and holding stages. The powder bed morphology, temperature distribution, and heat flux were calculated.

2. The model is validated through simulation of particle flow and heat conduction in the powder bed, and the simulated results are in good agreement with either experiment in the literature or finite element method.

3. The effect of laser power on the temperature distribution of the powder bed was 
studied. The average temperature in the powder bed increased with higher laser power.

4. Increasing laser scan speed does not affect the heating rate in the powder bed since the energy input is kept same.

5. Increasing laser hatch spacing will not affect the average temperature in the powder bed. However, a large hatch spacing may cause discontinued temperature distribution and microstructure inhomogeneity.

Although this study presents new insights of the temperature fields in the DMLS process, the model has several limitations, which could be investigated in future studies. For example, the model assumes a uniform laser power source, while actual laser source has a power intensity distribution. Additionally, non-uniform particle size can be considered to take particle size distribution into account. Furthermore, the size of powder bed is small with a relatively few numbers of particles compared to reality. An increased number of particles in the powder bed would be ideal when the corresponding computational power is available. 


\section{Acknowledgement}

JZ acknowledges the financial support provided by Walmart Foundation (project title:

Optimal Plastic Injection Molding Tooling Design and Production through Advanced Additive Manufacturing). The authors are deeply indebted to the anonymous reviewers for their meticulous and constructive comments. 


\section{References}

1. Simchi, A., F. Petzoldt, and H. Pohl, On the development of direct metal laser sintering for rapid tooling. Journal of Materials Processing Technology, 2003. 141(3): p. 319-328.

2. Karapatis, N., J. Van Griethuysen, and R. Glardon, Direct rapid tooling: a review of current research. Rapid Prototyping Journal, 1998. 4(2): p. 77-89.

3. Khaing, M.W., J.Y.H. Fuh, and L. Lu, Direct metal laser sintering for rapid tooling: processing and characterisation of EOS parts. Journal of Materials Processing Technology, 2001. 113(1-3): p. 269-272.

4. Gu, D. and Y. Shen, Effects of processing parameters on consolidation and microstructure of $\mathrm{W}-\mathrm{Cu}$ components by DMLS. Journal of Alloys and Compounds, 2009. 473(1): p. 107-115.

5. Jenkins, J. and S. Savage, A theory for the rapid flow of identical, smooth, nearly elastic, spherical particles. Journal of Fluid Mechanics, 1983. 130: p. 187-202.

6. Bi, G., et al., Microstructure and tensile properties of superalloy IN100 fabricated by micro-laser aided additive manufacturing. Materials \& Design, 2014. 60: p. 401-408.

7. Dinda, G.P., A.K. Dasgupta, and J. Mazumder, Laser aided direct metal deposition of Inconel 625 superalloy: Microstructural evolution and thermal stability. Materials Science and Engineering: A, 2009. 509(1-2): p. 98-104. 
8. Murr, L.E., et al., Fabrication of Metal and Alloy Components by Additive Manufacturing: Examples of 3D Materials Science. Journal of Materials Research and Technology, 2012. 1(1): p. 42-54.

9. Megahed, M., et al., Metal additive-manufacturing process and residual stress modeling. Integrating Materials and Manufacturing Innovation, 2016. 5(1): p. 1.

10. N'Dri, N., et al., DMLS Process Modelling \& Validation, in TMS2015 Supplemental Proceedings. 2015, John Wiley \& Sons, Inc. p. 389-396.

11. Zohdi, T., Additive particle deposition and selective laser processing-a computational manufacturing framework. Computational Mechanics, 2014. 54(1): p. 171-191.

12. Herbold, E., O. Walton, and M. Homel, Simulation of Powder Layer Deposition in Additive Manufacturing Processes Using the Discrete Element Method (Report Number: LLNL-TR-678550). 2015, Lawrence Livermore National Lab.(LLNL), Livermore, CA.

13. Manne, A. and N. Satyam, A Review on the Discrete Element Modeling of Dynamic Laboratory Tests for Liquefaction Assessment. EJGE, 2015. 20(21-46).

14. Harthong, B., et al., Modeling of high-density compaction of granular materials by the Discrete Element Method. International Journal of Solids and Structures, 2009. 46(18-19): p. 3357-3364.

15. Parteli, E.J.R. and T. Pöschel, Particle-based simulation of powder application in additive manufacturing. Powder Technology, 2016. 288: p. 96-102. 
16. Vedachalam, V., Discrete Element Modelling Of Granular Snow Particles Using LIGGGHTS. M. Sc. thesis, University of Edinburgh, 2011.

17. Kloss, C., et al., Models, algorithms and validation for opensource DEM and CFD-DEM. Progress in Computational Fluid Dynamics, an International Journal, 2012. 12(2-3): p. 140-152.

18. Brilliantov, N.V., et al., Model for collisions in granular gases. Physical review E, 1996. 53(5): p. 5382.

19. Silbert, L.E., et al., Granular flow down an inclined plane: Bagnold scaling and rheology. Physical Review E, 2001. 64(5): p. 051302.

20. Zhang, H. and H. Makse, Jamming transition in emulsions and granular materials. Physical Review E, 2005. 72(1): p. 011301.

21. Chaudhuri, B., F.J. Muzzio, and M.S. Tomassone, Modeling of heat transfer in granular flow in rotating vessels. Chemical Engineering Science, 2006. 61(19): p. 6348-6360.

22. González-Montellano, C., et al., Validation and experimental calibration of $3 D$ discrete element models for the simulation of the discharge flow in silos. Chemical Engineering Science, 2011. 66(21): p. 5116-5126.

23. Bontha, S. and N.W. Klingbeil. Effect of a Distributed Heat Source on Melt Pool Geometry and Microstructure in Beam-based Solid Freeform Fabrication. in Annual International Solid Freeform Fabrication Symposium, The University of Texas, Austin, Texas. 2006. 
24. Foroozmehr, A., et al., Finite Element Simulation of Selective Laser Melting process considering Optical Penetration Depth of laser in powder bed. Materials \& Design, 2016. 89: p. 255-263.

25. Streek, A., P. Regenfuss, and H. Exner, Fundamentals of Energy Conversion and Dissipation in Powder Layers during Laser Micro Sintering. Physics Procedia, 2013. 41: p. 858-869.

26. Zeng, K., et al. A new dynamic mesh method applied to the simulation of Selective Laser Melting. in 24th International SFF Symposium - An Additive Manufacturing Conference, SFF 2013. 2013. 


\section{List of Figures}

Figure 1: Flow chart of the DEM simulation of DMLS process in this study.

Figure 2: Particle flow validation model. (a) hopper dimensions (unit: mm), (b) discharge of partilces from the hopper.

Figure 3: Temperature distribution and evolution of thermal conduction simulation using DEM and FEM.

Figure 4: Top view of the powder bed dimensions (unit: $\mathrm{mm}$ ) used in the DMLS process model. Laser scan path is represented by the red line.

Figure 5: Temperature distributions in the DMLS process simulations. (a) vertical deposition of particles, (b) recoating process, (c)laser heating of particles, and (d) holding period. The particles are labeled using colors to present their temperature (unit: K).

Figure 6: (a) Temperature distribution (unit: K), and (b) heat flux distribution (unit: W) using $300 \mathrm{~W}$ laser power.

Figure 7: (a) Temperature distribution (unit: K), and (b) heat flux distribution (unit: W) using $100 \mathrm{~W}$ laser power.

Figure 8: Average temperature of the powder bed versus time for $100 \mathrm{~W}$ and $300 \mathrm{~W}$ laser powers. 
Figure 9: (a) Temperature distribution (unit: K) and (b) heat flux distribution(unit: W) using $1000 \mathrm{~mm} / \mathrm{s}$ laser scan speed.

Figure 10: (a) Temperature distribution (unit: K) and (b) heat flux distribution(unit: W) using $800 \mathrm{~mm} / \mathrm{s}$ laser scan speed.

Figure 11: Average temperature of the powder bed versus time using $800 \mathrm{~mm} / \mathrm{s}$ and 1000 $\mathrm{mm} / \mathrm{s}$ laser scan speeds.

Figure 12: (a) Temperature distribution, and (b) heat flux distribution using $0.1 \mathrm{~mm}$ hatch spacing.

Figure 13: (a) Temperature distribution, and (b) heat flux distribution using $0.2 \mathrm{~mm}$ hatch spacing.

Figure 14: Average temperature in the powder bed versus time using $0.1 \mathrm{~mm}$ hatch spacing and $0.2 \mathrm{~mm}$ hatch spacing. 


\section{List of Tables}

Table 1: Material parameters of 15-5 PH1 used in the simulations 
Graphical abstract

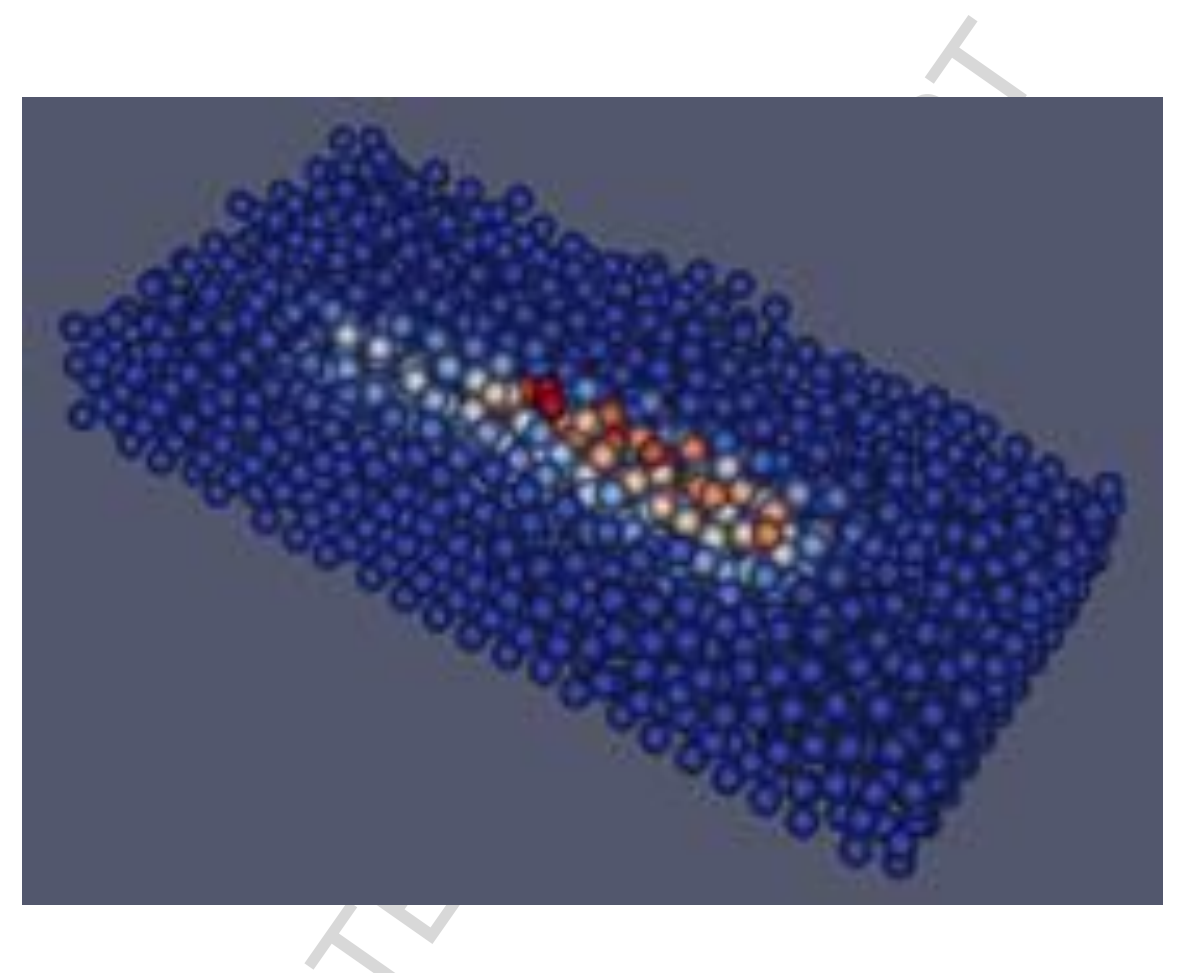

Temperature distributions during DMLS process simulation

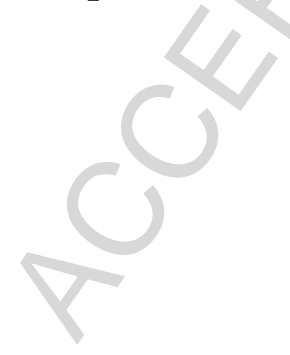




\section{Highlights}

- A novel particle-based discrete element model (DEM) is developed for DMLS process

- Effects of laser power, scan speed, hatch spacing on powder temperature are studied

- The model provides a powerful tool for DMLS process design and optimization 